\title{
Can We? Administrative Limits Revisited
}

The idea of administrative limits-in the sense of constraints or bounds on what can be achieved by the activity of administration in general and public administration in particular - is important for a proper understanding of twenty-first-century public administration. What are the effective limits of taxable capacity in the modern state, as debt-ridden governments seek to reduce debt levels and budget deficits after the financial crashes and economic recession of the late 2000s? What are the limits of safety and security that can be realistically achieved by administrative structures and procedures in a so-called risk society? What are the limits to the achievement of ambitious social engineering to improve the human lot by conventional organizations and bureaucracies? Such issues are not new. Questions of this kind have long been asked by scholars in the intersecting fields of public administration, policy studies, and political science. Nonetheless, the author argues, they address issues that are of continuing, central importance to government and society in today's world.

$\mathrm{N}$ atural scientists can tell us why-and where-there are limits on the extent to which thickening lenses can increase magnification; on how small a viable warm-blooded mammal could be produced by selective breeding; and on the degree of absolute discrimination (e.g., in judgments of pitch, volume, or saltiness) that human cognitive systems are capable of. Indeed, it can be argued that the concept of limits-where they are, why they are where they are, and how far they can be changed - is a central issue in all scientific thinking.

The idea of administrative limits-in the sense of constraints or bounds on what can be achieved by the activity of administration in general and public administration in particular-is important in our field, too. What are the effective limits of taxable capacity in the modern state, as debt-ridden governments seek to reduce debt levels and budget deficits after the financial crashes and economic recession of the late 2000s? What are the limits of safety and security that can be achieved by administrative structures and procedures in a so-called risk society? What are the limits of ambitious social engineering by conventional organizations and bureaucracies to improve the human lot? Such issues are not new. Questions of this kind have long been asked by scholars in the intersecting fields of public administration, policy studies, and political science. Nonetheless, they address issues of continuing and central importance to government and society in today's world.

On top of such perennial but still important questions, novel public policy issues thrown up by social and technological developments (such as genetic safety or cybercrime) keep on raising questions about administrative limits in new contexts. A notable example is the current fevered debate about how states should respond to the threat of damaging climate change and global warming. Of course, much that is being debated concerns the validity and reliability of climate science models (the accuracy of the parameters, the robustness of the causal links) and the arcane politics of international decision making over the setting of emissions reduction targets. But a key part of the debate also concerns whether, how, and how far it is feasible to achieve the sort of human compliance needed to meet the targets that those international decision makers are wrangling over in their cliff-hanging summits.

The idea of administrative limits — in the sense of constraints or bounds on what can be achieved by the activity of administration in general and public administration in particular-is important in our field....
For example, in the absence of some massive technological breakthrough providing renewable energy at the same cost as fossil fuel energy (which is not currently possible; see MacKay 2009), what sort of control and surveillance measures would it actually take to return carbon

\section{Administrative Limits Revisited: A Senior-Junior Exchange}

Christopher Hood has taught public administration on three continents, and for the past five years, he has been director of the Economic and Social Research Council's Public Services Research Programme in the United Kingdom. He published The Limits of Administration in 1976, and since then, he has published widely on executive government organization, regulation, and public sector reform. His latest book, The Blame Game, will be published in 2010 by Princeton University Press.

E-mail: christopher.hood@all-souls.ox.ac.uk 
emissions in developed countries to the levels of the first half of the 1800 s, as the more ambitious climate targets imply? Could such changes be achieved in ways that would be relatively invisible to most people, on the long-standing principle of at-source income or sales taxation, or would they require major administratively directed controls on individual behavior of a kind and on a scale hardly seen in Western developed countries since the 1940s? If the latter, given that estimates of the size of the "black" or "shadow" economy (outside the reach of taxation or regulation) even in wealthy countries average 15 percent or so of gross domestic product for the OECD (Organisation for Economic Co-operation and Development) states (see Dell'Anno and Schneider 2003; Schneider and Enste 2002) and show little sign of declining, just how much compliance would be enough for those targets to be achieved? Could sufficient compliance be achieved by light-touch approaches following the "nudge" principle (Thaler and Sunstein 2008), or would it take a state with the sort of extreme social intrusiveness represented by, say, Calvin's Geneva or Mao's Cultural Revolution China? Such issues can hardly be dismissed as technical or peripheral.

Of course, where administrative limits lie and what form they take is something that is inherently contested, and limits can take several forms. If we distinguish between what is technically possible given sufficient resources and strong enough political backing and what is practically possible given the interaction of public attitudes or political dynamics with normally available administrative capacity (see Hood 1976, $10-13$ ), it is the second kind of administrative limits that most obviously play into the politics of the developed Western democracies over heavily contested issues such as climate change or financial regulation. But more technical limits sometimes emerge, too, for instance, in shaping what is feasibly taxable and how far or how quickly complex public service systems can be reprogrammed (e.g., in switching from driving on one side of the road to driving on the other side, as Sweden did in 1967 and Okinawa did in 1978).

Many, perhaps most, ideas about the limits of administration are normative, belonging in the tradition of Wilhelm von Humboldt's (1851) classic Enlightenment-era ideas about the limits of state action. They concern what can properly be achieved by the state or other administration (e.g., what may legitimately be done to monitor people's activity or shape their behavior) rather than what can actually be achieved, properly or otherwise. Obviously, it is difficult to separate the normative from the positive, as is shown by Victor Thompson's (1975) well-known and provocative argument, which challenged the New Public Administration movement of the early 1970s (Marini 1971) by claiming that ordinary bureaucracies are not capable of being "kind" and "caring," and therefore should not pretend to be. Such difficulties of untangling normative and positive claims raise the obvious question of whether the idea of administrative limits can ever be more use as an analytic concept than as a sort of litmus or knee-jerk test for cultural or ideological bias, to separate those with an ideological propensity to favor big-government, state-engineered solutions to society's problems from those who are more skeptical about that sort of approach.

To that, it might be said that litmus tests and their equivalents have a central role to play in science, and if the idea of administrative limits did no more than offer the basis of a reliable test of ideological outlooks, that would itself be far from valueless. But the divide over the limits of administration may not be as simple as that, for at least two reasons. One is that (as can apply in natural sciences too) the assertion or denial of administrative limits may be as much rhetori$\mathrm{cal}$ as ideological. That is, it can be so much a reflection of some all-encompassing view of the world (in the way that, say, feminism or Marxism are) as forms of persuasion advanced by particular interests. For example, Corporation A, seeking permission to sell its potentially hazardous products, may assert that regulators can effectively impose complex user requirements that will ensure the safety of its products (e.g., by requiring all users to wear space suits or follow equally onerous procedures), while Corporation B, seeking to fend off threats to its business from regulatory proposals (e.g., to limit children's consumption of junk food), may assert that there are no feasible administrative means for achieving such purposes. Which side of the "limits of administration" debate you are on may be as much about interest as ideology, and may vary from case to case.

The other reason for questioning a simple litmus test view is that, on closer reflection, any ideological divide over administrative limits may involve more than the difference between those who believe in big government as it is ordinarily understood and those who prefer small government, important though that distinction no doubt is. Different cultural or ideological biases prompt us to see different kinds of administrative limits, to see limits in different places, or even to use the same types of limits to draw different policy conclusions. Given that production or service delivery processes in government and public services are typically constrained by a number of factors and not just one, which is to be counted as the most limiting factor? Public sector labor unions are programmed to identify resource limits as the critical factor, while taxpayers' associations are programmed to identify other kinds of limits. And if we find limits in securing compliance in some domain (e.g., in the observation of buffer zones for crop spraying or fraud in transfer payments), when is that outcome to be used as a policy argument for scrapping the program or banning the product, when is it to be taken as an argument for doing the same thing in a different way (e.g., through more "techno-regulation"), and when is it to be taken as an acceptable position? There are more than two ideological ways to look at administrative limits.

Further, while it is undeniable that the concept of administrative limits has a strong rhetorical or ideological dimension, even the academic literature of management and administration is full of more or less explicit claims about the limits of control and organization. One example, perhaps the central proposition of classical management theory (Urwick 1943, 52-3) and the point of departure for principal-agent theory a generation later, is the idea that the "span 
of control" is inherently limited even for the most capable managers, and consequently no large organization can ever be fully controlled from a single point.

Limits were also central to, the "contingency theory" of organization that developed from the late 1950s in the aftermath of Herbert Simon's (1946) famous assault on the proverbs of administrative theory. Simon brought out a different aspect of administrative limits in positing what was in effect a "dilemma theory," countering the have-it-all view that there is some all-purpose form of organization that works well for all tasks and environments, and in particular arguing that the sort of organization that works well in a stable and predictable environment could not be expected to function successfully in a different habitat.

Simon's ideas about bounded rationality in human decision making also delineated limits on calculative planning and strategizing, as emphasized by many other authors in the mid-twentieth century, such as Karl Polanyi and Charles Lindblom. Policy implementation theorists of the 1970s and 1980s, notably Jeffrey Pressman and Aaron Wildavsky (1973) and Eugene Bardach (1977) analyzed the gap between what is desired and what is feasible and tended to stress the limits of complex administrative coordination and the consequent need to design policies that recognize such limitations. That theme is reflected in Bardach's $(1977,253)$ argument for the design of programs that require as little management as possible and do not rely on high levels of competence and rapid coordination, echoing Pressman and Wildavsky's often-quoted remark, "If policy analysts carry bumper stickers, they should read, 'Be Simple! Be Direct!' or 'Payment on Performance"' $(1973,159)$. So the idea of administrative limits can be found in the work of serious administrative theorists - it is not just the province of more obviously ideological thought.

\section{What Causes Administrative Limits?}

Public administration (and management, for that matter) has often been said to be a subject matter rather than a discipline in the orthodox sense (of an analytic ABC) in which history and mathematics are disciplines (Waldo 1968, 2). While we have numerous mesotheories, administrative science has always had to draw heavily on other bodies of thought for generic theoretical and analytic ideas. To identify what causes administrative limits, we can draw on at least three basic ways of thinking about the issue from ideas about control in other partially intersecting disciplines, namely, cybernetics, economics, and theories of cultural or organizational variability.

Cybernetics and the idea of "requisite variety." For cybernetics, the science of general control systems that developed in the 1940s and came to be widely applied to the analysis of organization and administration in the 1960s - for example, in Stafford Beer's numerous works $(1966,1972)$ and in works by other authors, such as Karl Deutsch (1966) — the central idea about administrative limits comes from W. Ross Ashby's (1956) famous law of requisite variety. This "law" is the proposition that control-conventionally defined as the ability to keep the state of some system within some desired subset of all possible states - is limited by channel capacity or variety in the sense of the number of states that a controlling unit is capable of taking up relative to the system that it aims to control. The law states that control is possible only when or to the extent that the variety (number of possible states) of the controlling entity matches that of the entity to be controlled. So, for example, if the human brain has a raw computational power of $10^{13}$ to $10^{16}$ operations per second (as is conventionally estimated), a robot or computer that is capable of fully matching a human being (e.g., in strategic gaming) would need to be able to select from at least $2^{50}$ different responses in any given second; at present, even supercomputers fall far short of that capacity.

The classical management theory proposition about the limits of the span of control in organizations can be readily, indeed precisely, derived from this law (as can the limits on absolute judgments, in the examples given at the outset). The law similarly describes the problem that is the point of departure for the "principal-agent" analysis that has been the source of so much influential institutional economic analysis over recent decades. (Principal-agent theory aims to explicate the scope and limits of controls, such as optimum reward theory, that can overcome or bypass inherent information asymmetries between "principals" of various kinds and the agents who nominally work for them, such as voters relative to elected officeholders, elected officeholders relative to bureaucrats, managers relative to frontline workers.) Requisite variety has even been used by some cultural theorists to identify inherent limitations associated with monocultural institutional structures (see Thompson, Ellis, and Wildavsky 1990; Verweij and Thompson 2006).

How has the requisite variety problem been affected by the development of modern information technology (IT) systems, which are, of course, themselves products of cybernetic ideas? After all, that development has been one of the most dramatic shifts in the way administrative systems operate since many of the older works cited earlier were written, and it can be argued that it has become as central to today's systems of government and administration as the road network was to the Roman Empire or the post office was to the Caliphate (Hanne 2007). IT developments have occasioned much discussion of a radically new age of administration, both from academic theorists and from reform practitioners, many of whom have attached great significance to the role of IT in moving government and administration from "industrial-era bureaucracies to the information age," in the well-known words of the U.S. National Performance Review of 1993.

Such developments allow data to be brought together and used in new ways that would not have been possible (or at least would have been infinitely more laborious) in the days of paper files and telephones, and can greatly reduce the cost of some interventions by government or other organizations that target groups of individuals through social sorting or zero-touch approaches (Hood and Margetts 2007, 184-85). Two examples of such new, limit-changing applications include the development of more or less continuous spot markets in electric power (a product that cannot be readily stored once generated) and pay-as-you-drive urban congestion charge systems that link cameras to computers and then to vehicle registration databases. The same sort of technological developments (cameras, computers, satellite technology) can also be used to change the landscape of control over frontline and street-level bureaucrats' behavior by higher administrative levels - for instance, in the form of software systems that sharply limit the discretion of such individuals that was emphasized by classic writers such 
as Herbert Kaufmann in The Forest Ranger (1960) and Michael Lipsky in Street-Level Bureaucracy (1980). This suggests that IT developments can sometimes give controllers access to greater informational variety relative to the systems they are trying to control.

Digital technology, the big development of the past generation, thus appears to have some significant limit-breaking capacity in administration. But that does not mean the new information state is free of administrative limits altogether —only that the limits are different. After all, even a digital state must work through the medium of natural as well as machine language, and the inherent limits of specificity in human language (which have so fascinated philosophers and psycholinguists since the days of Jeremy Bentham) mean that the categorization and rule specification on which administration necessarily depends will remain subject to those limits. Nor will the requisite variety problem disappear as long as those who enter and process data cannot be fully monitored by central system controllers, however elaborately they may try to check for data fabrication or gaming.

Further, the development and troubled history of many mega-IT projects in government has been a clear case of a lack of requisite variety, as between those who commission such developments and the corporations and engineers who supply the systems (see Dunleavy et al. 2006; Margetts 1999). And as the development of computer viruses and other "malware" has demonstrated, the weapons of the digital state can be turned against it to dramatic effect by hackers, saboteurs, and other cybercriminals (Hofmann 2010). Finally, the digital state depends on power supply in two senses: the literal one, referring to sources of electricity (without which all of its computers and cell phones would be just so much junk), and the broader one, referring to a physical presence to track down and deal with noncompliance and to operate in real as opposed to virtual mode when the latter does not secure compliance. We certainly should not discount the changes that digital-era government can make in the limits of administration. But those changes do not necessarily alter the less technical kinds of administrative limits noted at the outset. Even for those more technical limits, the dramatic alteration that the digital era brings to some of the production possibilities (such as joining up back-office functions) is accompanied by new limits imposed by the cost, effort, and time needed to make structural changes in complex information systems (e.g., tax and benefit systems).

\section{Economics and the idea of variable or diminishing returns. As} noted earlier, economics has become ever more preoccupied with administration and organization since the days, not much more than half a century ago, when it was conventional to treat the firm as if it were a single individual and when concern with organizations and bureaucracies more broadly was confined to a few individuals on the fringe of the discipline as it was then conceived. Much of the development of institutional economics since that time has come from the boom in principal-agent analysis, which stems from the requisite variety problem noted earlier. The development of transaction-cost analysis has been concerned with exploring the implications for organization and administration of relaxing the once-conventional assumption in economics that transactions are costless, assuming away the administration problem (see, e.g., Horn 1995). Economic ideas about institutions and credible commitments (Levy and Spiller 1996; North 1993) represent another way of thinking about some of the limitations of state administration and how they can be circumvented.
But arguably the most central, distinctive, and traditional proposition about administrative limits that comes out of economics is the idea of diminishing or variable returns to effort and investment. This commonly invoked idea, encountered by every Economics 101 student, is conventionally traced back to David Ricardo's "law of diminishing returns" in his 1815 Essay on the Influence of a Low Price of Corn on the Profits of Stock, which states that additional units added to any factor of production (when the others are kept constant) will produce increases in overall output that eventually diminish to the point at which overall output starts to fall. The more general point is that the return or utility gained from adding units of consumption, investment, or effort often will not be linear, and indeed typically will tend to decline as additional units are added.

The idea of variable and diminishing returns is also an idea of central importance for analyzing the limits of administration. In some conditions, there can be increasing returns from investment or effort-for example, when demonstration or multiplier effects operate or when moving up a scale of effort or investment can cross a critical mass threshold to overcome limitations of small scale. That is what is behind ideas about troop surges in military campaigns, saturation policing in public order control, or organizational amalgamations to pool resources for greater impact in domains such as drug control or workplace safety. But diminishing returns commonly attend administrative efforts, too, particularly in securing compliance or behavior change. Light-touch "nudge" type initiatives often produce far less than 100 percent compliance, and moving beyond that point usually requires the deployment of heavier-duty (and typically scarce) resources. The idea of diminishing returns can help us to pinpoint why the kind of administrative project or policy for which the last 5 percent or 10 percent of compliance is vital to success is often so difficult to achieve without major negative side effects (see, e.g., Breyer 1993).

If cybernetic ideas have been reflected in the development of IT systems that have transformed government and administration over the last 30 years, economic ideas have been important, too. Indeed, another of the big changes over that period has been the growth of the so-called New Public Management. That movement has been variously described by its numerous exponents, advocates, and detractors, but it is often seen as placing increased emphasis on ideas from economics and business management. Among the economic ideas commonly associated with the movement are pay-for-performance systems in the public sector, market testing and competitive contracting in place of permanent bureaucratic provision, and attempts to produce partial substitutes for competitive markets, 
such as tournament competitions through rankings or league tables, voucher systems, and "quasi-markets."

Such changes have been much discussed in the extensive literature on New Public Management changes over the past few decades. But while those changes may in some cases push out the productionpossibility frontier for public services (evidence is patchy at best), they do not remove that frontier or eliminate the phenomenon of diminishing returns. Indeed, the logic of the diminishing returns approach implies a need for a clearer recognition of administrative limits and an avoidance of too many measures that depend for their success on that last 5 percent-or even 20 percent — of compliance or behavior change.

Sociocultural analysis and the idea of social contingency. A rather different perspective on administrative limits can be drawn from ideas about administrative or corporate culture or ways of life in sociology and anthropology. After all, culture in the sense of shared attitudes and beliefs about how to behave or how to see the world has long been viewed in social science as one of the primary regulators of human behavior. Thus, it is not surprising that it has been a central feature of much management, administrative, and political theory from the outset (for example, in the work of Mayo 1949 and Crozier 1964) and continues to be so.

The ideas of contingency theory in administrative science, and broader, more general ideas about different and conflicting worldviews or ways of life in society, offer a perspective on the limits of administration different from the two mentioned earlier. Contingency theory developed as a major field of analysis in administrative science during the 1960s and 1970s. It was a key part of the response to Herbert Simon's call for more systematic research to resolve the apparent contradictions in the precepts of older management science, and it resulted in extensive attempts to measure different dimensions of organizational structures against measures of the environment and technology (see, e.g., Hall 1972).

The term "contingency theory" is hardly used today. Part of the reason for that seems to be that, beginning in the 1980s, rational choice-style analysis became more prominent in organizational theory relative to the sociological tradition from which the $1960 \mathrm{~s}$ and 1970s contingency theory researchers had come. The disappearance of the term may also be attributable to changes in terminology, as organizational variability analysis came to be used under different headings, such as high-reliability theory and Henry Mintzberg's (1993) famous "structure in fives" approach to management, which drew from contingency theory but did not use the term. Another reason may be the overshadowing of the industrial-sociology approach of the early contingency theorists by broader analyses of varying and conflicting "ways of life" in social organization. An influential source of such broader analysis began its modern existence in the work of the anthropologist Mary Douglas. Douglas linked Émile Durkheim's sociological analysis (particularly his classic early twentieth-century analysis of fundamentally different forms of religious life; see Durkheim [1912] 1995) to detailed studies of colonial-era anthropology in order to produce a new analysis of cultural variety and conflict. She argued that by combining two fundamental dimensions of social organization, we can identify four basic and fairly universal ways of life-belief systems linked to forms of social organization - that exist in tension or in conflict with one another and have different strengths and weaknesses.

Since Douglas's original exposition of her "grid-group theory," way of life analysis has burgeoned across the social sciences, including administrative and policy studies, where it was enthusiastically adopted by the late Aaron Wildavsky and several of his collaborators (e.g., Webber and Wildavsky 1986; Wildavsky and Swedlow 1991). It has been applied to many problems and contexts and has also undergone various refinements, modifications, and challenges. For instance, Marco Verweij and Michael Thompson (2006) argued that organizational arrangements that combine different ways of life (which they term "clumsy institutions") can outperform monocultural arrangements. More radically, Mike Pepperday (2009) argued that the four basic "ways of life" identified by grid-group theory are universal in that they can be readily derived from social dimensions other than grid and group, and that there must logically be three rather than two underlying dimensions to produce those four basic types.

Such analyses aim to pinpoint the limits of any single organizational design or way of life and to show that what works well for some purposes or some social contexts will not work equally well for other purposes or contexts. Of course, this basic idea is far from new-after all, Kenneth Burke long ago remarked that "people may be unfitted by being fit in an unfit fitness" $(1984,10)$. But its elaboration has been a notable feature of recent decades, and it elucidates some of the basic trade-offs or dilemmas of administrative design.

Thus, for way of life theory, each of the basic types-hierarchism, egalitarianism, individualism, and fatalism, as they are commonly called, although there are variations in terminology — has its built-in limitations that are the obverse of its strengths when it is used as a basis of organization. The hierarchist way offers orderly structures and the decision capacity that goes along with an emphasis on the line-of-command approach. But it is correspondingly vulnerable to failures stemming from misplaced trust in authority and expertise, which often lie at the heart of big project fiascos, such as the so-called Concorde fallacy of dealing with a problematic project by committing ever more resources to it (Dawkins and Brockmann 1980). The egalitarian way can be conducive to general buy-in by organizational members and maximum openness to everyone's views, but it is correspondingly vulnerable to the sorts of failures that stem from the inability to control feuding, break deadlocks, or deal with opportunistic free-riding. The individualist way offers free rein to the individual creativity and entrepreneurship that can be stifled by hierarchist or egalitarian forms of organization, but it is correspondingly vulnerable to the sort of collapse that comes from tragedy of the commons failures or systemic risk stemming from lack of collective response capacity. The fatalist way (to the extent that it is applicable to the conscious design of organization and administration) can offer defenses against corruption, traditionally the central problem of public administration, because it works against the development of mutual trust within corrupt cliques that is a prerequisite for most forms of systemic corruption. But it is correspondingly vulnerable to failures stemming from inertia and passivity in the face of major threats or opportunities (see Hood 1998, 28ff). 
The implication of such analysis is that there is no cost-free design for organizational and institutional arrangements, and that each of the main forms available has an Achilles heel that goes along with the advantages it has to offer. Compared with the first two approaches, it is harder to identify clear-cut developments over the past 30 years that have aimed to change the limits identified by this sort of analysis. It is true that the "corporate culture" movement of the 1980s_epitomized by Thomas Peters and Robert Waterman's controversial In Search of Excellence (1982), which sold 3 million copies in its first four years-arguably encouraged managers and organizational designers to take culture seriously, and some cultural theorists have called for a deliberate mixing of ways of life into organizational design. But the extent to which culture is "engineerable" seems to be limited, and the logic of way of life analysis suggests that, at the margin, the different ways of life are incompatible, such that the advantages of one can only be obtained by giving up the advantages of the others.

Further, it could be argued that there are a number of significant administrative limits that are constituted by the incompatibilities of conflicting administrative desiderata or values (see Hood and Jackson 1991, 12-14), which may loosely reflect the concerns of different ways of life and are often institutionalized into different domains-for example, when the values of flexibility and pragmatism run up against "due process" values, as in procurement, land use, or regulation, so that one set of values acts as a limit for the achievement of others. That sort of conflict is often involved in the idea of "wicked problems," as formulated by Horst Rittel and Melvin Webber (1973) and later developed by many others, where there is no definitive formulation and conflicting worldviews prevail. For Andrew Dunsire $(1978,227)$, such value conflicts are the only way that bureaucracies can be effectively controlled-but the opposite side of that coin is a form of administrative limit.

Summary. These three types of analysis do not, of course, exhaust the possible generic sources from which we can reason about administrative limits and their causes, and it is debatable whether these three are the most important ones, but all of them merit some attention. Moreover, each of these three types also points us toward rather different types of limits. The law of requisite variety that is the central idea of cybernetic theory is, in a sense, an absolute limit, like the law of gravity. We cannot escape from it-we can only work around it in various ways.

On the other hand, the notion of variable or diminishing returns that comes from economics is not an absolute limit in that sense, but rather identifies nonlinearities in the relationship between effort or investment and reward. Governments and administrators can, in principle, ignore diminishing returns and go on pursuing goals such as securing extra compliance by posting police officers, tax collectors, or security guards at every street corner, and indeed, that happens when the stakes are high enough. But if compliance is problematic and resources are finite, that option cannot be pursued for every administrative goal.

Contingency or way of life analysis points to a third kind of limit, namely, dilemmas - the situation, common in medical and other forms of science, in which alternative designs, values, or courses of action have opposite patterns of strength and weakness but cannot readily be combined, running against the search for "have-it-all" solutions that political reformers are always looking for. After all, as noted earlier, value or domain conflicts are often central to limiting administration. Creative mixes may be possible sometimes, but as the hapless melon farmers in Gustave Flaubert's novel Bouvard et Pécuchet (1910) discovered when they inadvertently mixed up tomatoes and different sorts of melons, not all hybrids are successful.

So what kinds of limits we find where is likely to remain a central and contested issue in administrative analysis. For instance, the debate about the scope and limits of the "high-reliability organization" turns precisely on whether we should think of administrative limits as universals (as Charles Perrow's influential 1984 argument about "normal accidents" suggested) or as dilemmas. Thompson's (1975) response to the New Public Administration ideas of the 1970s, noted earlier, also turns on whether limits on bureaucratic capacity are to be seen as absolutes, nonlinearities, or dilemmas. And more recent debates about using technological fixes versus human behavioral change also turn on whether the limits on the latter are absolutes, nonlinearities or dilemmas.

\section{Limits of Administration: A Limiting Perspective?}

Is it, in fact, limiting to focus on the limits of administration? It might seem a thoroughly wet-blanket, glass-half-empty, party-pooping line of thinking that goes against more upbeat, accentuatingthe-positive approaches to administration. It is perhaps redolent of the old joke about the British civil service being an organization programmed to produce "a problem for every solution." Does that sort of focus risk turning the study of administration into a new "dismal science," as economics used to be labeled, at least before the creation of so-called hedonomics?

There are several possible answers to that question. First, it follows from the analysis described earlier that, while the law of requisite variety implies real and absolute limits of control, that is not necessarily the critical or most constraining limit for many types of policy problems. Moreover, many administrative limits are not fixed for all time, nor are they the same in all social contexts (Thompson 1975, 93-94, made exactly this point at the conclusion of Without Sympathy or Enthusiasm).

For example, the administrative limits of taxable capacity (the basis on which most public administration rests) vary with economic structure and other social conditions that determine how "canalizable" or readily appropriable key economic transactions are. A case in point is the invention of the steam pump, which effectively killed salt taxation (once a fiscal staple) in England during the nineteenth century because, thereafter, salt could be produced cheaply anywhere, not just in the "spas" or brine springs to which it had hitherto been confined (see Hughes 1934). The development of betting over the Internet in the 1990s likewise destroyed the effective basis of taxes on racecourse betting that had previously been practicable to collect. 
But social developments can go in the other direction, too, creating the administrative basis for new or more effective taxes. Indeed, during the twentieth century, a set of interrelated social changes made taxes far easier for governments to collect-namely, a widespread move from peasant farming to urban societies with largely monetized economies and, more specifically, the growth of big employing, producing, and retail organizations with internal control systems that readily lent themselves to acting as conduits for at-source income or sales taxation, plus economies based on the internal combustion engine and therefore on oil that was readily taxable as it moved from the point of extraction to the point of consumption through ports or pipelines (see Hood 2003).

Of course, those twentieth-century developments that were so favorable to the growth of the "tax state" may not be reproduced in the societies of the information age, potentially changing the administrative limits of taxable capacity. It remains to be seen whether Internet providers could be the fiscal equivalent of the oil companies for the twenty-first century, and whether effective digital-age equivalents of stamp taxes, the great Dutch fiscal invention of the seventeenth century (De Vries and Van der Woude 1997), can be devised. It remains to be seen, too, whether the much-discussed development of low-cost personal genomic testing will prove to be a more secure way of establishing identity than current methods, given the importance of identity to most administrative processes.

A second response to the charge that a focus on administrative limits implies an excessively negative "no we can't" perspective is that there can be heuristic and theoretical advantages to conceiving what the world would be like without administrative limits, as in the literature on utopias and just as economic analysis can fruitfully draw on the concept of perfect competition or physics uses the concept of a perfect vacuum as a means of describing any given vacuum. That is not because limitless administrative capacity is ever likely to be a realistic description of what the world is actually like, any more than is perfect competition in economics or a perfect vacuum in the physical world, except in vanishingly rare conditions. It is because such an analysis can help us pinpoint what or how much difference it makes when administration is less than perfect in specific ways, as safety engineers do when they apply fault tree analysis to complex systems.

If we apply that kind of analysis to the sorts of issues set out at the start of this essay-for instance, about ways of handling cybercrime, genetic safety, and climate change, not to mention the financial collapses of the late 2000 s_we may find that the balance among absolute limits of the requisite variety kind, nonlinearities of the diminishing returns kind, and dilemmas or value conflicts of the kind represented by way of life theory varies from case to case or from one domain to another.

Of course, many of those kinds of administrative limits are currently beyond the reach of precise measurement and prediction. But that does not mean they do not exist. Indeed, perhaps we need more precise thinking about just what would need to be known for those different kinds of limits to be measurable, in the same way that some of the great nineteenth-century physicists such as PierreSimon Laplace and James Clerk Maxwell were able to specify the knowledge that would need to be possessed by an entity capable of measuring items that were of key significance to propositions in theoretical physics in their day (notably, what would have to be known to reveal all past and future cosmic events in the first case, and to disprove the second law of thermodynamics in the second case).

Of course there are limits to administrative analysis as well as the activity of administration. But regardless of whether we can measure them, it is still important to be able to identify different types of administrative limits and to explore how their relative importance varies under different circumstances. Limits or constraints should be as central to administrative science as they are to other sciences, because limits and opportunities are opposite sides of the same coin (Hood 1976, 206) and because limits become most interesting when we start to push up against

them. And it should be a central task of administrative science to show how and why such limits vary.

\section{Acknowledgments}

I am sincerely grateful to Eugene Bardach, Geert Bouckaert, Ruth Dixon, Grant Jordan, Per Lægreid, Martin Lodge, Michael Moran, Ed Page, Alasdair Roberts, and Fred Thompson for their valuable and perceptive comments on a previous draft of this paper.

\section{References}

Ashby, W. Ross. 1956. An Introduction to Cybernetics. London: Chapman and Hall.

Bardach, Eugene. 1977. The Implementation Game: What Happens after a Bill Becomes a Law. Cambridge, MA: MIT Press.

Beer, Stafford. 1966. Decision and Control: The Meaning of Operational Research and Management Cybernetics. London: Wiley.

- 1972. Brain of the Firm: The Managerial Cybernetics of Organization. London: Penguin.

Breyer, Stephen G. 1993. Breaking the Vicious Circle: Toward Effective Risk Regulation. Cambridge, MA: Harvard University Press.

Burke, Kenneth. 1984. Permanence and Change: An Anatomy of Purpose. 3rd ed. Berkeley: University of California Press.

Crozier, Michel. 1964. The Bureaucratic Phenomenon. London: Tavistock.

Dawkins, Richard, and H. Jane Brockmann. 1980. Do Digger Wasps Commit the Concorde Fallacy? Animal Behaviour 28(3): 892-96.

De Vries, Jan, and Ad van der Woude. 1997. The First Modern Economy: Success, Failure, and Perseverance of the Ditch Economy, 1500-1815. Cambridge: Cambridge University Press.

Dell'Anno, Roberto, and Friedrich Schneider. 2003. The Shadow Economy of Italy and Other OECD Countries: What Do We Know? Journal of Public Finance and Public Choice 21(2-3): 97-120.

Deutsch, Karl. 1966. The Nerves of Government: Models of Political Communication and Control. 2nd ed. New York: Free Press.

Douglas, Mary. 1982. Cultural Bias. In In the Active Voice, by Mary Douglas, 183-254. London: Routledge.

Dunleavy, Patrick J., Helen Margetts, Simon Bastow, and Jane Tinkler. 2006. Digital Era Governance: IT Corporations, the State, and E-Government. Oxford: Oxford University Press.

Dunsire, Andrew. 1978. Control in a Bureaucracy. Oxford: St. Martin's Press. 
Durkheim, Émile. [1912] 1995. The Elementary Forms of Religious Life. Ed. and trans. Karen E Fields. New York: Free Press.

Flaubert, Gustave. 1910. Bouvard et Pécuchet. Paris: Louis Conard.

Hall, Richard H. 1972. Organizations: Structure and Process. Englewood Cliffs, NJ: Prentice Hall.

Hanne, Eric J. 2007. Putting the Caliph in His Place: Power, Authority, and the Late Abbasid Caliphate. Madison, NJ: Fairleigh Dickinson University Press.

Hofmann, Jeanette. 2010. Et in Arcadia Ego: From Techno-Utopia to Cybercrime. In Paradoxes of Modernization: Unintended Consequences of Public Policy Reform, edited by

Helen Margetts, Perri 6, and Christopher Hood, 81-100. Oxford: Oxford University Press.

Hood, Christopher C. 1976. The Limits of Administration. London: Wiley.

1998. The Art of the State: Culture, Rhetoric, and Public Management. Oxford: Clarendon Press.

. 2003. The Tax State in the Information Age. In The Nation-State in Question, edited by T. V. Paul, G. John Ikenberry, and John A. Hall, 213-33. Princeton, NJ:

Princeton University Press.

Hood, Christopher C., and Michael J. Jackson. 1991. Administrative Argument. Aldershot, UK: Dartmouth.

Hood, Christopher C., and Helen Z. Margetts. 2007. The Tools of Government in the Digital Age. Basingstoke: Palgrave Macmillan.

Horn, Murray J. 1995. The Political Economy of Public Administration: Institutional Choice in the Public Sector. Cambridge: Cambridge University Press.

Hughes, Edward. 1934. Studies in Administration and Finance, 1558-1825, with Special Reference to the History of Salt Taxation in England. Manchester: Manchester University

Press.

Kaufman, Herbert. 1960. The Forest Ranger: A Study in Administrative Behavior. Baltimore: Johns Hopkins University Press.

Levy, Brian, and Pablo T. Spiller, eds. 1996. Regulation, Institutions, and Commitment: Comparative Studies of Telecommunications. Cambridge: Cambridge University Press.

Lipsky, Michael. 1980. Street-Level Bureaucracy: Dilemmas of the Individual in Public Services. New York: Russell Sage Foundation.

MacKay, David J. C. 2009. Sustainable Energy—Without the Hot Air. Cambridge: UIT Ltd.

Margetts, Helen Z. 1999. Information Technology in Government: Britain and America. London: Routledge.

Marini, Frank, ed. 1971. Toward a New Public Administration: The Minnowbrook Perspective. Scranton, PA: Chandler.

Mayo, Elton. 1949. The Social Problems of an Industrial Civilization. London: Tavistock.

Mintzberg, Henry. 1993. Structure in Fives: Designing Effective Organizations. Englewood Cliffs, NJ: Prentice Hall.

North, Douglass C. 1993. Institutions and Credible Commitment. Journal of Institutional and Theoretical Economics 149(1): 11-23.

Pepperday, Michael E. 2009. Way of Life Theory: The Underlying Structure of Worldviews, Social Relations and Lifestyles. PhD diss., Australian National University.

Perrow, Charles. 1984. Normal Accidents: Living with High-Risk Technologies. New York: Basic Books.

Peters, Thomas J., and Robert H. Waterman, Jr. 1982. In Search of Excellence: Lessons from America's Best-Run Companies. New York: Harper \& Row.

Pressman, Jeffrey L., and Aaron Wildavsky. 1973. Implementation: How Great Expectations in Washington Are Dashed in Oakland. Berkeley: University of California Press.

Rittel, Horst, and Melvin Webber. 1973. Dilemmas in a General Theory of Planning. Policy Sciences 4: 155-69.

Schneider, Friedrich, and Dominik H. Enste. 2002. The Shadow Economy: An International Survey. Cambridge: Cambridge University Press.

Simon, Herbert A. 1946. The Proverbs of Administration. Public Administration Review 6(1): 53-67.

Thaler, Richard H., and Cass R. Sunstein. 2008. Nudge: Improving Decisions about Health, Wealth, and Happiness. New Haven, CT: Yale University Press.

Thompson, Michael, Richard Ellis, and Aaron Wildavsky. 1990. Cultural Theory. Boulder, CO: Westview Press.

Thompson, Victor A. 1975. Without Sympathy or Enthusiasm: The Problem of Administrative Compassion. University: University of Alabama Press.

Urwick, Lyndall F. 1943. The Elements of Administration. London: Pitman.

Verweij, Marco, and Michael Thompson, eds. 2006. Clumsy Solutions for a Complex World: Governance, Politics and Plural Perceptions. London: Palgrave Macmillan.

Von Humboldt, Wilhelm. 1851. The Limits of State Action. Breslau: E. Trewendt.

Waldo, Dwight. 1968. Scope of the Theory of Public Administration. In Theory and Practice of Public Administration, edited by John C. Charlesworth, 1-29. Philadelphia:

American Academy for Political and Social Science/American Society for Public Administration.

Webber, Carolyn, and Aaron Wildavsky. 1986. A History of Taxation and Expenditure in the Western World. New York: Simon \& Schuster.

Wildavsky, Aaron, and Brendan Swedlow. 1991. Is Egalitarianism Really on the Rise? In The Rise of Radical Egalitarianism, edited by Aaron Wildavsky, 63-98. New

Brunswick, NJ: Transaction Books.

Never Stop Learning...!

ASPA Conference Papers

The 2010 Annual conference had over 100 applied practice workshops,

panel sessions, and discussion circles on a wide variety of topics

in Public Administration.

Watch for the release of Conference Papers at:

http://www.aspanet.org 